\title{
Defining Pedagogic Expertise: Students and New Lecturers as Co-Developers in Learning and Teaching
}

Followed by Student Response by Aaron Long

\section{ABSTRACT}

This study evaluated a model of student-engaged educational development. Despite widespread commitment to student engagement across many institutional activities, student participation as partners with faculty in teaching and learning enhancement has been identified as a threshold concept for educational development. This study sought not only to establish a student-engaged model of teaching observation in a United Kingdom context, but also to critically examine the ways in which student, faculty, and developer participants conceptualise student expertise in relation to learning and teaching. Concept-map mediated interviews with students and faculty in humanities and healthcare subjects elicited conceptions and comparative knowledge structures of pedagogical intelligence for the purposes of enhancing teaching practice. The outcomes of the study are considered in relation to the theorisation of student engagement with particular focus on perspectives of expertise and power relations.

\section{KEYWORDS}

educational development, expertise, student-faculty partnership, teaching observation, power relations

\section{INTRODUCTION}

As a counter to the rhetoric of "student as consumer" that has emerged as a result of the introduction of student tuition fees in the United Kingdom (UK), a more participative agenda emphasising student voice and the student experience propose that working with students has the potential to be transformative. Emerging examples demonstrate how students can be integrated into educational change as participants and experts as well as partners and agents. For example, students have assumed collaborative roles in curriculum design and development (Bovill, Cook-Sather, \& Felten , 2011) and pedagogic evaluation (Bovill, Aitken, Hutchison, Morrison, Roseweir, Scott, \& Sotannde, 2010). However, some have noted that models of educational development continue to operate on the basis that students do not have an active role in informing the learning of academic faculty (CookSather, 2011).

The absence of student engagement in educational development practice in the UK is beginning to be addressed in a number of recent examples (Alsford, 2012; Freeman, Millard, Brand, \& Chapman, 2014; Dickerson, Jarvis, \& Stockwell, 2016). Educational development activities that engage students allow for the exploration of the nature of pedagogic expertise as well as for the professional role of both lecturers and educational developers in the enhancement of learning and teaching. Previous research on students as pedagogic consultants, predominantly in United States (US) contexts, has suggested that the 
principal benefit to teachers is access to student insights on teaching that can inform teacher reflective practice and professional learning (Cook-Sather, 2008).Where student-faculty collaborations have taken place, the engagement of students as consultants also "catalyzes a revision of students' relationships to their teachers and their responsibilities within their learning” (Cook-Sather \& Alter, 2011, p. 37). In particular, students-as-consultants in the enhancement of learning and teaching can expose the "complexities of power balance in the student-teacher relationship" (Crawford, 2012, p. 53). For students, the benefits of participation in such activities can include the development of learners' skills, knowledge, and values, as well as increased agency in shaping their learning experience and the reconfiguring of student-faculty power relationships in the classroom (Barnes, Goldring, Bestwick, \& Wood, 2010).

Partnership initiatives and interventions involving students as pedagogic consultants are growing and widely praised (Healey et al, this issue), but usually focus on the experiences and benefits for students. In line with the student-focus of such initiatives, faculty perspectives on student partnerships are less likely to be solicited. There has also been limited investigation of faculty and student participants' conceptions of students' expertise or to what extent they can participate in enhancement activities. With a predominant focus on descriptive rather than evaluative accounts, previous research on student engagement has also not fully acknowledged the complex realities of teaching expertise and authority, particularly for new faculty, when locating faculty-student dialogue at the heart of student partnership (Taylor \& Robinson, 2009; Seale, 2010).

Recognising that the language of empowerment and agency underpinning student voice work is not neutral, such activities, therefore, pose important methodological and theoretical questions for advocates of the broader agenda of student engagement. For example, drawing on Fielding's (2004) work on student voice in schools, the pragmatic decision to work in partnership with a few students as representatives of all students means that student pedagogic consultants are potentially co-opted into the normative practice of speaking for and about others as subjects, rather than as transformative agents that challenge existing beliefs about the learning needs of a diverse student cohort. This study responds to that gap in our understanding by exploring how both faculty and students conceptualise the expertise that students might bring to teaching through participating in student-engaged professional development.

\section{Understanding expertise and partnership}

Student participation in enhancement activities with faculty is a threshold concept-a 'conceptual gateway' that leads to a transformed view or understanding (Meyer \& Land, 2006) — for educational development because "it contradicts prevailing notions that students do not have understanding or experience to inform teaching practice and that faculty developers or colleagues are best positioned to inform and guide faculty" (Cook-Sather, 2014, p. 189). Co-inquiry into learning and teaching in partnership with students, however, can be transformational for both participating faculty and students (Werder, Thibou, \& Kaufer, 2012).

In defining student-faculty partnership, Cook-Sather, Bovill and Felten (2014) warn that "we need to acknowledge that our roles, expertise, responsibilities, and status are different" (p. 7), yet the act of "partnership brings these forms of experience and expertise into dialogue" (ibid). From this perspective, they argue that "students are neither disciplinary nor pedagogical experts. Rather, their experience and expertise typically is in being a student” (p. 15). This defines student expertise as a particular expression of their experience of being in the academy. In this study we interrogated the 
dialogue between student, faculty, and developers and their conceptions of the different expertise students bring to the understanding and enhancement of teaching.

This study began from the hypothesis that the conceptions of the actors involved in the development of pedagogic practice (students, new faculty, and developers) concerning the nature of this practice as expertise would inform the transformational potential of these encounters.

If student expertise is a threshold concept in this context, however, we also recognise that the selfconcept of new faculty and educational developer as disciplinary and pedagogic experts may be both tentative and mutable within the complex and hierarchical social order of the university.

As they begin their careers, academic faculty identities are likely to be unstable and can be repeatedly problematised during their socialisation into the academy (Smith, 2010). The shifting identity formation of new teaching faculty as they progress through a formal educational development qualification is shaped by the requirement to inhabit new teacher and researcher identities. For some new teachers, particularly those undertaking doctoral research, the slippage between teacher and learner can be particularly acute. Where a teacher's own identity and sense of disciplinary and pedagogic expertise is developing or in flux, the balance of student and teacher authority in the classroom is not straightforwardly defined. Similarly, educational developers' conceptions of their role, expertise, and status can be equivocal. Their role in identifying and critiquing pedagogic practice and influencing the relationships between faculty and students is often undertaken in highly politicised institutional and sector contexts (Debowski, 2014). In this context, underestimating the ability of students to contribute to the enhancement of teaching and learning, as well as cynicism about institutional strategies for engaging students, can contribute to faculty resistance of partnership activities (Bovill, Cook-Sather, Felten, Millard, \& Moore-Cherry, 2015).

Partnership models of educational development_-bringing staff and students together for enhancement activities - while desirable in many respects, therefore, reimagine often hard-won positions of expertise and voice that educational developers have earned within institutions. Developers are hypothesised to have three potential roles in partnership activities: they may have a protectionist approach to their own status with the capacity ultimately to block the new lecturer-student relationship by positioning expertise as residing exclusively between the developer and the new lecturer. They may also act as an intermediary for student engagement by encouraging new lecturer-student interaction in academic practices and development by helping to structure opportunities for meaningful feedback and dialogue. Lastly, developers could act as mutual participants engaged with students and lecturers in the co-development of expertise and understanding within a more holistic learning community.

This study focuses on a collaborative approach to teaching observation where teachers, educational developers, and students define their roles and notions of expertise and provides an opportunity to better understand both the enablers and the barriers to partnership enhancement approaches. It responds explicitly to Trowler's (2010) suggestion that student engagement research has been predominantly normative and uncritically based on the assumption that all forms of student participation in learning are unequivocally positive. Likewise, Zepke and Leach (2010) have noted that student engagement approaches can focus on reporting operational concerns to the neglect of more critical explorations of the participatory and dialogic aspects of engagement between students, faculty, and developers.

\section{THE STUDY}

In this small-scale qualitative study, three undergraduate students (Maria, Nasir, and Zander) were recruited as pedagogic consultants for three new faculty in similar disciplines (Karen, Devyani, and 
Anya) as part of a postgraduate-level teaching qualification at a large, urban research-intensive university in the UK. Additionally, two educational developers (Damien and Simone) were full participants in the study, providing support and facilitating student-lecturer interaction in the enhancement activities. The aim was to explore and compare each of the eight participants' (three students, three new lecturers, and two developers) attitudes and perceptions of student-lecturer-developer collaboration in the enhancement of teaching practice over a sustained period of time (several academic terms) providing opportunities for reflection and change of perception. Institutional research ethics approval was obtained and pseudonyms are used to maintain the confidentiality of all the participants.

\section{Recruitment}

New faculty were invited to participate in the study as a result of their registration on a postgraduate teaching qualification, a requirement for all new incoming faculty at the institution. Due to high interest in the opportunity to work with students, the first three faculty who volunteered were selected to participate. This sampling approach reflected the constraints of conducting a small-scale study within a time-limited period. Student participants were then invited to participate through open recruitment to collaborate as co-developers. Students were selected from two discipline fields (humanities and health sciences subjects), which were related to the new lecturers' disciplines. The aim in selecting students on the basis of their disciplinary background was to support student understanding of the content and pedagogies of the teaching they were observing but to avoid any pre-existing relationship with the lecturers including formal teaching or marking relationships between the participating faculty and students. The students' experience varied, including a first-year, second-year, and final year student. The mix was intentional to explore the role of students' experience 'as a student' on their conception of their expertise.

All educational development staff in the department were invited to participate. Two educational developers agreed to participate. Several others were hesitant to participate due to concerns about their already-fragile role definition, and expressed concern that bringing students into the educational development-faculty relationship could undermine years of concerted effort to build trust in their expertise in the enhancement of teaching and learning.

\section{Process}

The study involved three concept-map based interviews with participants before, between, and after two planned professional development interventions. Each participant firstly participated in a developer-facilitated teaching observation. The three students each led a teaching observation with a new lecturer facilitated by an experienced educational developer with the aim to engage in collaborative dialogue about observed teaching practice (Cook-Sather, 2011). Subsequently, the students participated in a seminar with a larger group of new faculty. Each student attended the relevant seminar for their assigned teacher, which was led by one of the educational developers and had around 20 participants. Topics discussed during the seminar included the types of evidence teachers draw on to evaluate their practice and critical reflection on how teaching can be developed. Both activities were part of the new lecturer teaching qualification programme, a mandatory course for new teaching faculty to reflect on and develop their teaching practice. The seminar provided students with a better understanding of the context of professional development while also creating another opportunity for dialogue about teaching and learning between students, lecturers, and developers. These two different opportunities offered student-faculty developmental dialogue as well as the capacity to capture developing understanding of student expertise over several months (see Figure 1). 
Figure 1. The Study Design

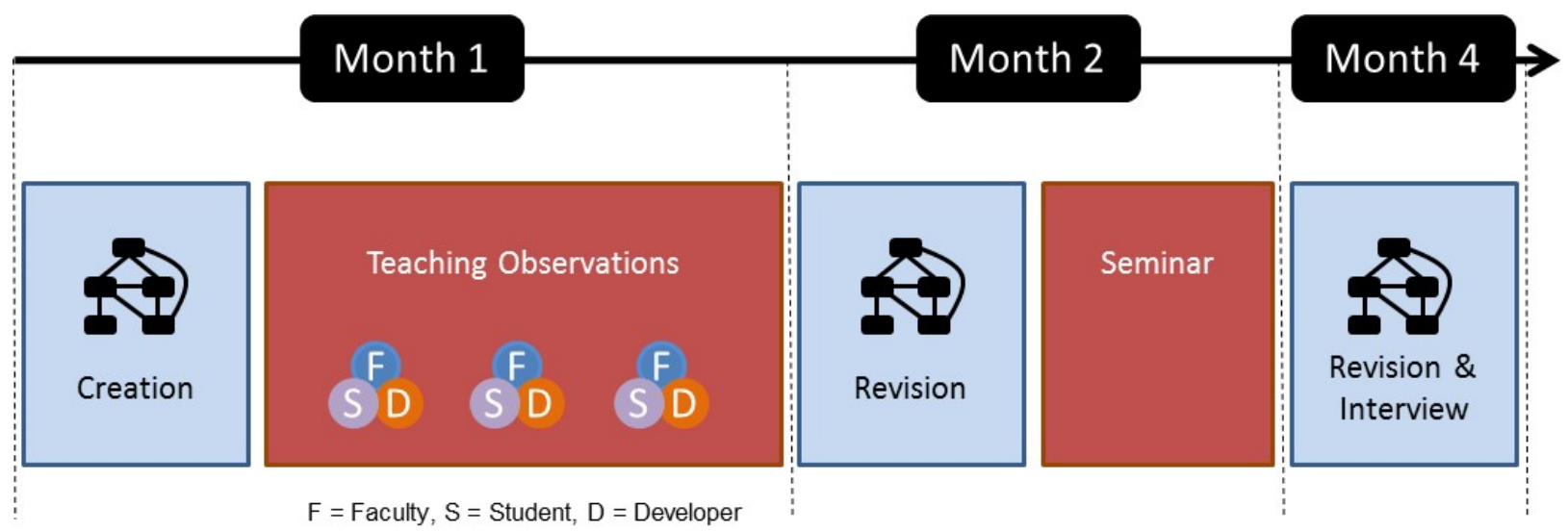

\section{Data collection}

Data collection was undertaken through repeated concept mapping during interviews. A concept map is a graphical tool that enables the expression of relationships between ideas by connecting boxed "concepts" with labelled links to create meaningful propositions (Davies, 2011). The method is quickly taught through example maps, and participants revisited and revised their concept maps throughout the study. Participants developed concept maps on pre-specified topics to elicit their conceptions of teaching and learning expertise. These were done at the beginning of the study, after the teaching observation, and again after attending the development programme seminar and concluded with a longer, recorded concept-map mediated interview. Each round of interviews involved participants developing and modifying concept maps responding to the following questions:

- What distinctive perspective can students bring to learning and teaching practice?

- What role can students play in enhancing learning and teaching?

- How is student voice represented within the institution?

After the first interview the participants (students, lecturers, and developers) could amend and update their previously created maps, leading to the generation of sixty-three maps in total from all participants over the series of interviews. The semi-structured concept-map mediated interviews (Kandiko \& Kinchin, 2013) utilised the iterative process of concept mapping at the beginning of the interview to then further explore perspectives specifically on pedagogic expertise and student-faculty collaboration in learning and teaching enhancement.

Concept mapping has been widely used to surface explicit perceptions of a range of issues in higher education (Kinchin, Streatfield, \& Hay, 2010; Kandiko \& Kinchin, 2013). In particular, concept map use within qualitative research can facilitate the eliciting of perceived importance of concepts and the visualising of the relationships between concepts (Wheeldon \& Ahlberg, 2012). The series of maps created by participants allowed for the visualisation of, and reflection on, change and development (or lack thereof) of participants' understanding of student expertise as students participated in a structured process of teaching enhancement. The maps were used repeatedly to explore with participants the complexities of their conceptions of student expertise in the enhancement of teaching and how lecturerstudent encounters might inform critical development of practice. It enabled interviewers and 
participants to explore possibilities and challenges visually to articulate relationships, hierarchies, and tensions between concepts and acts as a record of the interview.

\section{Analysis}

Analysis was done in a three-stage process. The recorded interviews were analysed for major themes, within and across the different participant groups. Similarly, the concept maps were analysed for themes within and across the participant groups - in terms of content, structure, and change over time. In the third stage the two sets of themes were compared. The emergent themes regarding notions of expertise and subsequent impact on power relations are explored in this paper.

\section{FINDINGS}

\section{The distinctiveness of student perspectives}

Participants articulated a range of ways in which students could provide distinctive perspectives into the learning experience. For many of the participants, engaging students in observing teaching provided opportunities for faculty to access the "student point of view" (Nasir, student). For faculty, the students "really pointed out things that I could have just forgotten about, you know, forgotten how the student would think or would receive that" (Devyani, lecturer). This opportunity to see teaching practice from different identity positions could be powerful and enlightening and was unavailable to teachers except from students.

Students could help teachers to see and interpret student behaviours from different physical spaces in the room as well as from the personal, lived experience of the students as learners. For Karen, her student observer Maria

picked up on kind of how the students seemed to be reacting, what she would have liked me to have done differently... they seemed particularly engaged in this bit and slightly less engaged in this bit, which is the sort of thing I find quite hard to notice. (Karen, lecturer)

Karen believed that the insights that Maria was able to offer were an outcome of her physical place in the room: she could see what the teacher could not while teaching, as well as explain her own reactions to the approach the teacher had taken as this related to her preferences as a learner.

Students also provided a more generic insight into the experiences of all learners. As the educational developer Damien noted, students "understand how they learn better than teachers do" and, for the student Nasir, "students know how they learn best and what to look for." The experience of working with the students led the educational developer to consider, using a stage metaphor that was repeated by other participants, that "sometimes our students are more expert and they deserve to have a space where they can behave as such. We should exit left and give them that space." This quote underscores an assumption that staff and developers have control of the learning environment and can 'allow' students to play a more active role.

The benefits of alternative insights were not unidirectional. Participation in teaching observation also enabled student participants to "get an understanding of how everything works behind the scenes" in terms of the sometimes difficult pedagogic decisions that teachers have to make (Nasir, student). This mutuality was echoed by the student Maria: "now I'm a lot more aware of what they [teachers] are made to do, how they're made to do it, you know, how they try to do it and I sympathise with them completely." These encounters signal that there are mutual blind spots, literal and conceptual. 
There are spaces in the teaching relationship where sightlines are blocked because of differences in knowledge and experience ("just forgotten") and the performative demands of the teaching experience ("behind the scenes"). Participating collaboratively in teaching observation, therefore, enabled participants to understand an important nexus between the experiences of teachers and students based around empathy, the capacity for a lecturer to remember the feelings of being a student, and sympathy, the capacity of a student to understand the experience of teachers within their workplace and role.

\section{Student "expertise" in learning and teaching}

While students had access to a different view of the learning experience, both faculty and students resisted framing this unique student perspective as a form of expertise. For example, Devyani argued that a developer could provide specific feedback on her practice that included the "fundamental points that you can maybe find in any teaching textbook." Mastery of disciplinary knowledge contributed to another lecturer's ability to give quality feedback during peer observation. As such, educational developers and lecturers are seen to have an expertise that is defined as essentially logicorational, forms of knowledge that encapsulate traditional "textbook" ways of knowing. For Damien, the expert identity of educational developers is complex and working collaboratively with faculty and students revealed the tensions between his responsibilities to enhance and affirm the teaching practice of colleagues while also occupying traditional expert identity as an academic staff member within institutional structures. He suggested

I think we have become... more expert, because what we do is, we now use this idea of being able to facilitate and listen and give our students power and voice. So our expertise is actually more prevalent... allows somebody else to show off their expertise. And yet we still have to be academics, we still have to be very aware of the fact that we have to present ourselves as Dr. $X$ as well, just because that's the context we work in. (Damien, developer)

Both faculty and student participants revealed the belief that students, on the other hand, would not

have the ability to know what to put in each year or how to rearrange the curriculum. It still needs a more expert person to say what they can learn and when. But [students] really could play a very important role on how this material should be taught maybe. (Devyani, teacher)

Likewise, when asked to define the expertise students might bring, a student argued

I'd put expert in quotation marks because I think expert implies, sort of, a familiarity with, I suppose, the knowledge base and teaching theory, because students by definition won't be familiar with the knowledge base, they're becoming familiar with it. And they're not necessarily familiar with ... teaching. (Zander, student)

Conversely, while expertise was related by participants to a mastery of the discipline or of pedagogic theory, student perspectives on the learning environment were described as specifically emotional and experiential. New teacher Karen commented, "I think [students] know how to give feedback on whether or not they've enjoyed a class and whether or not they feel like they've learned things, but I'm not sure they necessarily have the tools ... to say this bit of your teaching worked better than this bit." 
Nevertheless "that kind of feelings feedback is as useful as the specific kind of discipline feedback." She believed that students could articulate "the feeling in the room" as well as providing a "fresh perspective" expressed through a "similar language to the lecturer (no jargon)" (Figure 2). For faculty participants, students' apparent lack of disciplinary and pedagogic expertise and their alternative capacity to communicate feelings, therefore, was seen to be the real value of student contributions.

Figure 2. Final concept map on the distinctiveness of a student perspective (Lecturer Karen)

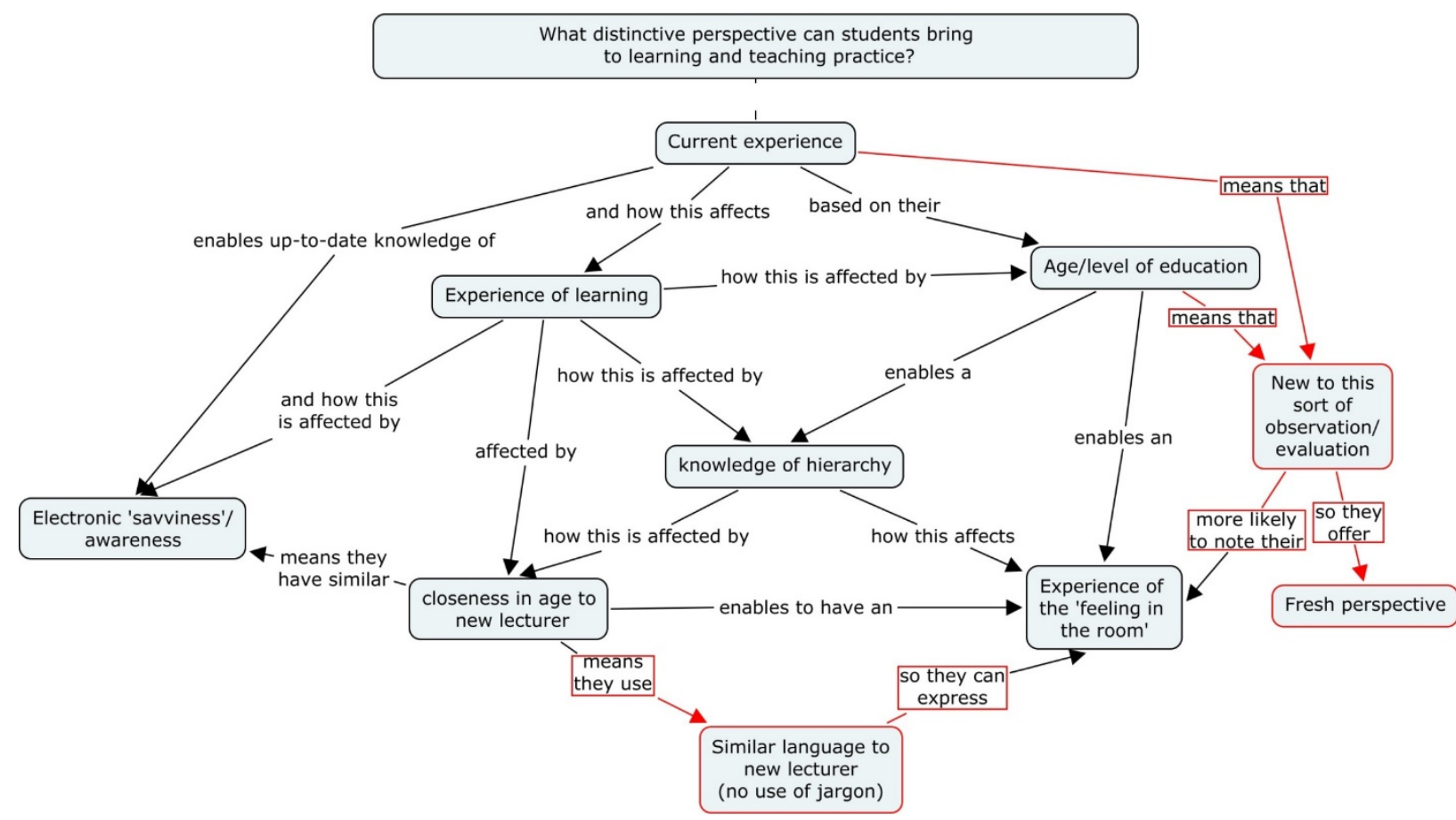

Balancing student-versus-expert perspectives in collaborative observation raised a tension for one teacher Anya, however, when the student observing her provided feedback she saw as more critically informed than she was expecting. She "was surprised, coming from a first-year student, this kind of, you know, these kind of things." The capacity of the student observer to comment beyond his personal experience and to explore the teaching he saw in more abstract or theoretical terms made him, Anya suggested, "atypical" and, while useful, she believed she would prefer feedback from an "average student" who might offer her the more expected experiential feedback described by other participants. This juxtaposition between the student having an individual, experiential, and affective perspective, and an expert with a theoretical, critical perspective on teaching was a construction of expertise belonging to knowledge-rich developers. Participants suggested that student consultants gave access to intuitive, personal, and, arguably, distinctly non-expert, un-trained views on teaching which could be "balanced" with what they defined as the more expert, disciplined voices of developers or peers. For the educational developer Damien, the feedback offered by students needed to be mediated through a more expert participant. He suggested

it makes a difference that we are there to facilitate and take the kind of... the absolute ownership of that process. And I also believe that, if we had just left these students to it... I'm not sure the 
process would have been so, you know, so well developed and it would have been so enriching. (Damien, developer)

Students can be active agents in the learning process such as in the role of partners in negotiating the curriculum, especially related to designing assessment activities, bringing more practical as well as emotional or experiential expertise. This role can be part of a mutually reinforcing engagement cycle that stimulates teachers and develops passion within students, as seen in Figure 3, disrupting traditional patterns of authority in teaching and learning. Possibly too disruptive was students engaging in the development seminar - the educational developers and the teachers found the students changed the dynamic in the room and that it ceased to be a safe space for reflection and communication about the challenges of teaching. However, as one lecturer noted, there is a critical point of how much students can be involved, and faculty and students alike noted that there can be poor student motivation to engage.

Figure 3. Final concept map on the role a student can play in enhancing teaching and learning (Student Maria)

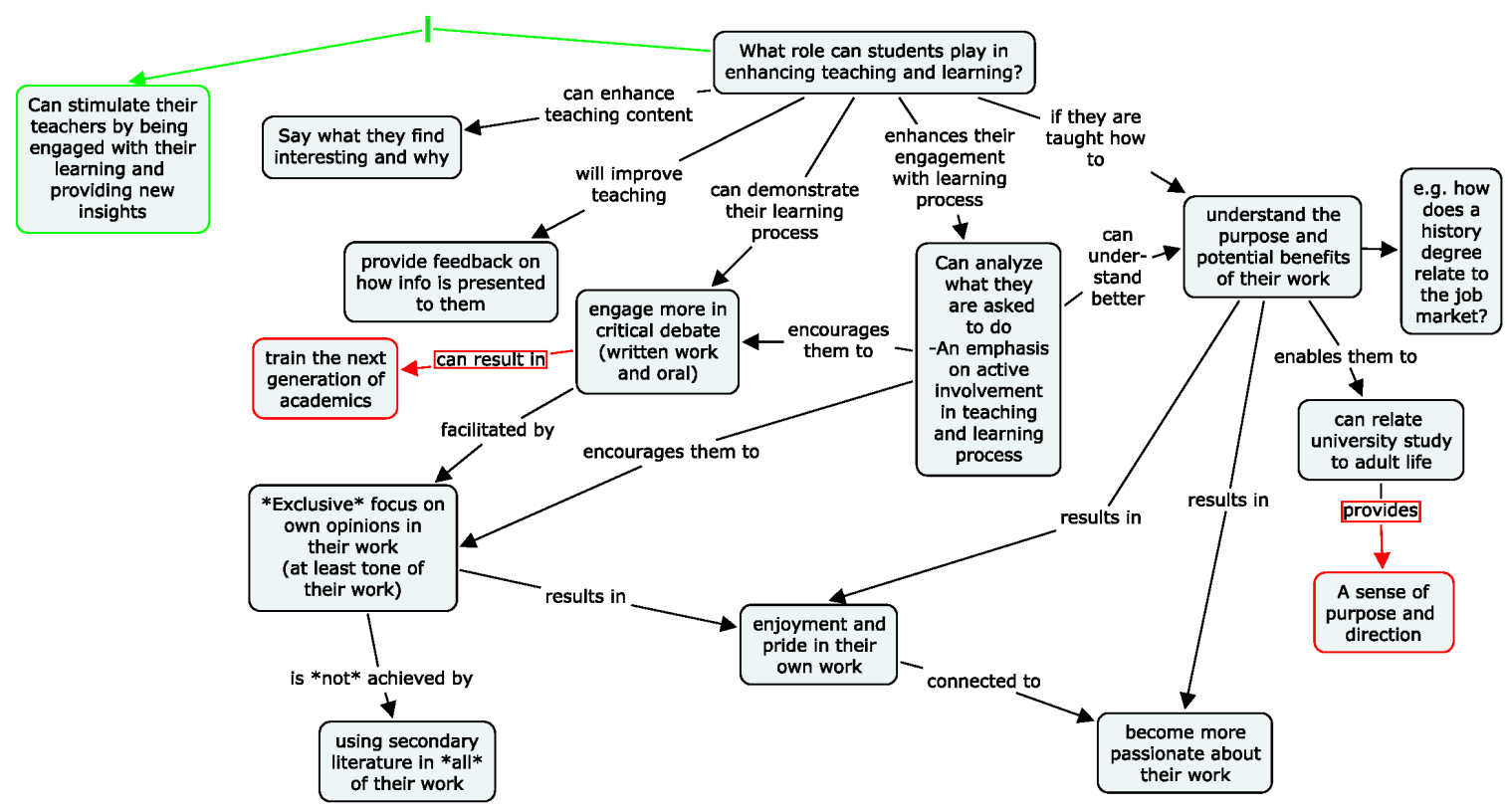

Despite the possibility of student-engaged educational development being a site of transformation, in this study the traditional notions of expertise were largely retained. For participants, developers offered the theoretical and practical expertise regarding teaching, whilst students provided experiential and affective situational expertise, with new lecturers operating in a liminal space in between. However, even given the tentative role formation for each group of participants, extant power relations regarding teaching both held strong and were not comfortably challenged. Nor did a need or desire for a transformation of roles or notions of expertise emerge.

\section{DISCUSSION}

Cook-Sather (2014) has identified the potential for knowledge derived from collaborative professional development to be troublesome, disruptive, and potentially transformative for teaching. 
This study revealed that, despite personally positive accounts, both students and faculty resisted ascribing student knowledge as "expertise" and continued to frame student roles and perspectives within traditional discourses of teaching and disciplinary authority. For example, students were seen as experts of a received content, but were not necessarily considered to be able to judge if it was the right content or if the teaching was effective for other students. In particular, it was the perceived naivety, non-expert views, and jargon-free insights into teaching that were valued by lecturers and students. Counter to a faculty and student resistance to the transformative potential of framing student input as "expertise" was a discourse that revealed and valued the relational aspects of the faculty-student interaction that were enabled through a partnership approach to teaching observation.

\section{Feedback dialogues}

The self-report of students and faculty suggests that the participation of students in feedback dialogues around observed teaching has the potential to access a different set of values of professional development, based on the emotional and experiential dimensions of learning. Participants found and valued what Bozalek, McMillan, Marshall, November, Daniels, and Sylvester (2014) describe as an "ethics of care" through the dialogic and "informal" mechanisms of the student-engaged model of teaching observation. This offers a valuable alternative to widely used measurable, instrumental and formal representational models of student feedback. It is a moral framework for educational development in universities as an alternative to discourses of accountability and the professionalisation of teaching. However, the educational developers' role in universities has itself emerged from this same neo-liberal agenda of teaching professionalism which provides significant leverage for educational developers' practice.

In our study, the developers' professional identities, based on the uniqueness of their pedagogic expertise, were juxtaposed with notions of students' expertise, as well as by the student-engaged pedagogic consultant model. Facilitation of interaction between faculty and students potentially presents a challenge to the role of developers as carriers and transmitters of pedagogic expertise. This was reflected in the difficulties experienced at the beginning of the study in recruiting educational developers to participate in the project and, even when developers were open to bringing students into the dialogue or recognising their specific types of expertise, a need to retain, as Damien describes it, "absolute ownership" over the observation process in practice or a need to define when and how student "expertise" is performed.

Our study suggests that the benefit of student involvement in the enhancement of teaching is dependent on the perceived authenticity of student voice within a circumscribed idea of student expertise. This is highlighted in the tension between the value faculty and developers found in accessing student naivety of perspective for informing practice versus students developing and articulating a "behind the scenes" understanding of pedagogy as the basis for a meaningful mutual learning experience for students and faculty. Although both forms of engagement may be beneficial, when students were thought to be "trained" as pedagogical experts offering informed rather than instinctive responses to the teaching they no longer fitted a perceived "authentic" student role. In the context of this study, the value of the student perspective on teaching is predicated on their lack of "expertise" in reaching critical judgements about the teaching and learning they are observing and the concomitant capacity for faculty and educational developers to translate these perspectives into meaningful principles for practice. 


\section{CONCLUSION}

Previous research has argued that when students are able to develop their voices and find a sense of pedagogic expertise, they can become active agents in teaching and learning enhancement. Students in clear roles providing formative feedback were beneficial for new teaching faculty seeking to understand how to improve their teaching. Yet this study has revealed that the engagement of students in enhancement activities does not, as a matter of course, engender the transformative negotiation of conceptual thresholds in relation to expertise, authority, or power in the classroom.

The process used here actually revealed limited, transmission-based models of faculty-student pedagogic interactions that did not change over the lifetime of the project despite perceived positive outcomes as a result of participating in student-engaged teaching observation for both faculty and students. Transformation may need more time to set in, or it may be limited by the ways in which faculty and students constructed their roles in the enhancement of learning and teaching, which explicitly reflected interference from an institutional, particularly managerial, agenda in tension with a moral or values-based relational model.

A challenge with the study was that the new faculty's professional development programme was not designed for student involvement, nor did it engage explicitly with critical pedagogy discourses that might inform the development of more transformational student-faculty collaborations. This project therefore revealed that the introduction of a partnership model of professional development did not automatically challenge the circumscribed and exclusive roles of lecturing faculty as experts. It did however suggest the importance of integrating into professional development a relational approach to pedagogic evaluation founded on the possibilities of emotional and intuitive faculty-student interactions as an extended form of pedagogic expertise. This model would position developers in greater facilitation roles, mediating expectations and possibilities, and pushing the boundaries of traditional pedagogic relationships.

This involvement of students in a student-engaged observation scheme was a partnership approach that still operated within, rather than against, neo-liberal discourses focused on possession of expertise as a capital for exchange rather than the potential for co-construction, shared or redefined through relational models of expertise. A greater sense of community may be needed, such as expanding students' responsibilities in the enhancement of teaching and learning, new teachers expanding their understanding of the expertise that students might bring, and developers assuming a more facilitative role.

Moving forward, it is recommended that future partnership activities should clarify what expertise is and what is the role for individual students and the collective student voice in the development and articulation of expertise. Initiatives would likely be more successful when faculty are partnered with students in clearly delineated projects that draw on their specific experiences. A wider ethos of partnership across an institution may need to be in place or a different focus for development activities, but that may not meet the needs of current expectations, existing practices, and desired outcomes. A development programme which explores the multiple identities and roles for new staff, being both teachers and students themselves, may be too complex an environment to support a transformative agenda. A 'refresher' course for more experienced teachers, or reconceptualising the learning and teaching space (and the roles of students and teachers) may be more conducive to transformational agenda-but both would also disrupt the existing roles for developers, teachers and students.

60 Kandiko Howson, C., \& Weller, S. (2016). Defining pedagogic expertise: Students and new lecturers as co-developers in learning and teaching. Teaching \& Learning Inquiry, 4(2). http://dx.doi.org/10.20343/teachlearninqu.4.2.6 
This study found both positive and negative challenges to power relations from bringing students on as co-developers of learning and teaching. This finding should provide a cautionary note that engaging students in such activities is not inherently a good thing and can be disruptive to enhancement agendas and individual development.

\section{ACKNOWLEDGEMENTS}

This study was supported by a grant from the Society for Research into Higher Education. The authors also thank Prof Ian Kinchin for his expertise in visualising powerful knowledge.

Camille Kandiko Howson is Academic Head of Student Engagement and Senior Lecturer at King's College London, UK.

Saranne Weller is Director of the Centre for Research Informed Teaching at London South Bank University, UK.

\section{REFERENCES}

Alsford, S. (2012). An educational development student forum: Working partnerships with students. Journal of Applied Research in Higher Education, 4(2), 186-202.

Barnes, E., Goldring, L., Bestwick, A., \& Wood, J. (2010). A collaborative evaluation of student-faculty partnership in inquiry-based educational development. In S. Little (Ed.), Faculty student partnerships in higher education (pp. 16-30). London: Continuum.

Bovill, C., Aitkin, G., Hutchison, J., Morrison, F., Roseweir, K., Scott, A., \& Sotannde, S. (2010). Experiences of learning through collaborative evaluation from a master's programme in professional education. International Journal for Academic Development, 15(2), 143-154.

Bovill, C., Cook-Sather, A., \& Felten, P. (2011). Students as co-creators of teaching approaches, course design and curricula: Implications for academic developers. International Journal for Academic Development, 16(2), 133-145.

Bovill, C., Cook-Sather, A., Felten, P. Millard, L., \& Moore-Cherry, N. (2015). Addressing potential challenges in cocreating learning and teaching: Overcoming resistance, navigating institutional norms and ensuring inclusivity in student-staff partnerships. Higher Education. DOI: 10.1007/s10734-015-9896-4.

Bozalek, V. G., McMillan, W., Marshall, D.E., November, M., Daniels, A., \& Sylvester, T. (2014). Analysing the professional development of teaching and learning from a political ethics of care perspective. Teaching in Higher Education, 19(5), 447-458.

Cook-Sather, A. (2008). 'What you get is looking in a mirror, only better:' Inviting students to reflect (on) college teaching. Reflective Practice, 9(4), 473-483.

Cook-Sather, A. (2011). Teaching and learning: College faculty and undergraduates co-create a professional development model. To Improve the Academy, 29, 219-232.

Cook-Sather, A. (2014). Student-faculty partnership in explorations of pedagogical practice: A threshold concept in academic development. International Journal for Academic Development, 19(3), 186-198.

Cook-Sather, A., \& Alter, Z. (2011). What is and what can be: How a liminal position can change learning and teaching in higher education. Anthropology \& Education Quarterly, 42(1): 37-53.

Cook-Sather, A., Bovill, C., \& Felten, P. (2014). Engaging students as partners in learning and teaching: A guide for faculty. San Francisco: Jossey-Bass.

Crawford, K. (2012). Rethinking the student-teacher nexus: Students as consultants on teaching in higher education. In M. Neary, H. Stevenson, \& L. Bell (Eds.), Towards teaching in public: Reshaping the modern university (pp. 52-67). London: Bloomsbury.

Davies, M. (2011). Concept mapping, mind mapping and argument mapping: What are the differences and do they matter? Higher Education, 62, 279-301.

Debowski, S. (2014). From agents of change to partners in arms: The emerging academic developer role. International Journal for Academic Development, 19(1), 50-56.

Dickerson, C., Jarvis, J., \& Stockwell, L. (2016). Staff-student collaboration: Student learning from working together to enhance educational practice in higher education. Teaching in Higher Education, 21(3), 249265. 
Fielding, M. (2004). Transformative approaches to student voice: Theoretical underpinnings, recalcitrant realities. British Educational Research Journal, 30(2), 295-311.

Freeman, R., Millard, L., Brand, S., \& Chapman, P. (2014). Student academic partners: Student employment for collaborative learning and teaching development. Innovations in Education and Teaching International, 51(3), 233-243.

Kandiko, C. B., \& Kinchin, I. M. (2013). Developing discourses of knowledge and understanding: Longitudinal studies of PhD supervision. London Review of Education, 11(1), 46-58.

Kinchin, I. M., Streatfield, D., \& Hay, D. B. (2010). Using concept mapping to enhance the research interview. International Journal of Qualitative Methods, 9(1), 52-68.

Meyer, J. H. F., \& Land, R. (2006). Overcoming barriers to student understanding. London: Routledge.

Seale, J. (2010). Doing student voice work in higher education: An exploration of the value of participatory methods. British Educational Research Journal, 36(6), 995-1015.

Smith, J. (2010). Forging identities: The experiences of probationary lecturers in the UK. Studies in Higher Education, 35(5), 577-591.

Taylor, C., \& Robinson, C. (2009). Student voice: Theorising power and participation. Pedagogy, Culture \& Society, $17(2), 161-75$.

Trowler, V. (2010). Student engagement literature review. York: Higher Education Academy. Wheeldon, J., \& Ahlberg, M. K. (2011). Visualizing social science research: Maps, methods, \& meaning. Sage.

Werder, C., Thibou, S., \& Kaufer, B. (2012). Students as co-inquirers: A requisite threshold concept in educational development. Journal of Faculty Development, 26(3), 34-38.

Zepke, N., \& Leach, L. (2010). Improving student engagement: Ten proposals for action. Active Learning in Higher Education, 11(3), 167-177.

\section{Student Response to "Defining Pedagogic Expertise: Students and New Lecturers as Co-Developers in Learning and Teaching"}

In responding to Howson and Weller's work, I feel the need to disclose my own role, an odd middle ground between the three perspectives considered by Howson and Weller's article: those of the "student," the "new faculty" member, and the "faculty developer." I am a graduate student at the University of Kansas (KU), teaching a 2-2 course load as part of my funding package. I also work parttime in faculty development as a Graduate Assistant for KU's Center for Teaching Excellence. Fifteen months ago I finished my last course as a student, so that experience is relatively fresh for me; however, I recognize that graduate student experiences may vary considerably from undergraduate student experiences, even in the same field.

I offer such a specific definition of my role at KU because I have questions about the definitions of "student," "faculty," and "faculty developer" in Howson and Weller's study. I wonder, for instance, whether the term "student" - even where it specifically means "undergraduate" —is still rather unspecific. Anyone who has taught both first-year and fourth-year undergraduates is aware there is a marked difference in the types of expertise an instructor can expect of these two populations. How 
would these findings vary depending on whether one studied students who had just arrived on campus after leaving home for the first time or studied students who were within a year of graduation? If the study was repeated with such specificity, how might it be replicated for non-traditional undergraduates? In what ways might differences among these populations not only reshape expectations for student "expertise" among "faculty" and "faculty developers," but also reveal a difference in students' ability to articulate their expertise?

Similar questions arose as I thought about the definition of "faculty developer." In our teaching center all faculty developers have teaching experience, and half of us are currently teaching while also helping to develop faculty. I wonder whether attention to the job descriptions of "faculty developers"or to whether or not they have tenure - in this and future studies might reveal experiences that are shaping findings, especially when those findings involve attitudes or assumptions about expertise or roles in the learning process.

The authors' specification of "faculty" as "new faculty" was helpful—clearly these faculty are not as susceptible to Richard Thaler's "endowment effect," as discussed by John Tagg in "Why Does the Faculty Resist Change?" (2012). But in what sense are "new faculty" really new? One of the reasons I chose my graduate program is precisely because it requires a 2-2 teaching load. My hope is that upon graduation I will be able to say that I have taught over twenty course sections in my discipline; experience on five faculty hiring committees in the past five years suggests viable candidates should be able to claim at least that much experience. Although I sense that the faculty members involved in this study are not the sort to resist changes in instructor or student roles, I suspect that even as "new faculty" they may already have experience-reinforced assumptions about those roles and the expertise that comes with each.

I wonder, in other words, about the degree to which the vocabulary used by SoTL scholars who make students part of the research team is freighted with assumptions born of longstanding university practices and power structures, and whether those involved in such studies can offer clear enough definitions to unmask the sources of the assumptions revealed in their findings. Inasmuch as it breaks down well-worn terms into more specific categories, it is iconoclastic, suggesting that newer, clearer SoTL terms might very well be revolutionary.

Aaron Long is a graduate student at the University of Kansas.

\section{REFERENCES}

Tagg, J. (2012, January-February). Why does the faculty resist change? Change: The Magazine of Higher Learning.

Copyright for the content of articles published in Teaching \& Learning Inquiry resides with the BY
have agreed that this article should be available on open access under a Creative Commons Attribution License 4.0 International (https://creativecommons.org/licenses/by/4.0). The only constraint on reproduction and distribution, and the only role for copyright in this domain, should be to give authors control over the integrity of their work and the right to be properly acknowledged and cited, and to cite Teaching \& Learning Inquiry as the original place of publication. Readers are free to share these materials-as long as appropriate credit is given, a link to the license is provided, and any changes are indicated. 